\title{
NEWS
}

\section{Cash crisis could ground NASA rocket}

\section{Crewed missions to the Moon are under threat, warns an expert panel.}

A committee of aerospace engineers and scientists was poised to deliver its grim assessment of NASA's human space-flight programme to US President Barack Obama on 8 September. The panel's report will outline the stark choices Obama will face, which could include cancelling a new system of Moon-bound rockets and all but giving up on exploring space beyond the low Earth orbit of the International Space Station (ISS).

"The bottom line is, they concluded that there's not enough money in the current budget to do anything useful in human space flight," says Marcia Smith, president of the Space and Technology Policy Group, a consultancy based in Arlington, Virginia, and former director of the Space Studies Board at the US National Research Council.

In May, Obama ordered the committee to review the current space policy set by former president George W. Bush, with its "vision" of building a Moon base as a prelude to sending people to Mars. The committee was tasked with assessing new scenarios - including using the ISS past its scheduled de-orbit in 2016 - while keeping to strict budget guidelines. Led by former aerospace executive Norman Augustine, the ten-member committee has not yet released its report, but public discussions this summer have made some of the options clear.

Given the budget constraints, the choices weren't pretty. In Obama's 2010 budget request, NASA's exploration programme, known as Constellation, would receive about US $\$ 6$ billion per year - about $\$ 1$ billion less than Bush asked for in his 2009 budget, and several billion less than what was slated in previous budgets (see chart). "The Bush budget stressed the system, but the Obama budget, if left as is, breaks it," says Scott Pace, director of the Space Policy Institute at George Washington University in Washington DC. One analysis by the committee showed that if the current plan and budget are kept, astronauts won't even leave low Earth orbit until 2028.

So the panel looked at alternatives, narrowing down some 3,000 permutations to just a handful for presidential digestion. In several scenarios, the Ares I rocket - one of two needed to take cargo and astronauts to the Moon - would be cancelled. Instead, money would be poured into commercial space companies, such as Space Exploration Technologies of Hawthorne, California, and Orbital Sciences in Dulles, Virginia,

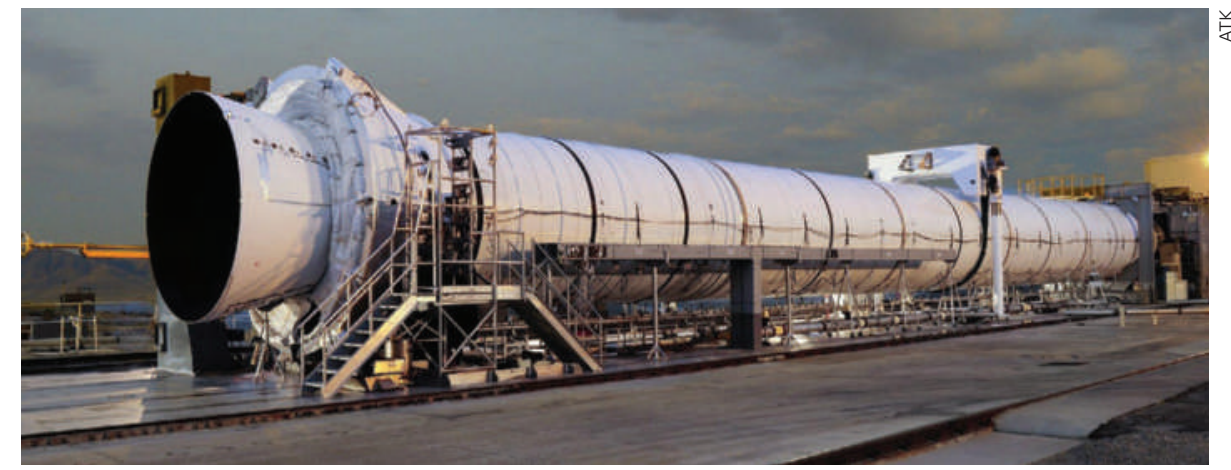

Current projects such as NASA's Ares I rocket could be cancelled in favour of commercial space flights.

which are already trying to build rockets to take cargo to the ISS. But the committee also seems inclined to support commercial rockets that could ferry people into space, says Smith.

Former NASA administrator Michael Griffin says there are risks not just in making a crewed commercial rocket a reality, but also in ceding the capability for space travel — traditionally held by the US government - to the private sector. "I am not a fan of attempts to rely on such a capability before it actually exists," says Griffin, now a professor of aerospace engineering at the University of Alabama in Huntsville. He says he would also be disappointed if Ares I were cancelled, not so much for the $\$ 6$ billion that has already been spent on the rocket and its Orion crew capsule, but because

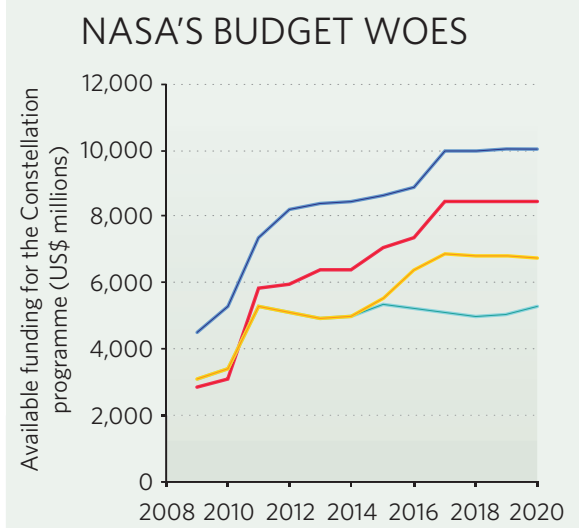

Funding expected when the Constellation exploration programme was outlined in 2005

- FY2009 budget request

- FY2010 budget request

Estimate if International Space

Station is kept operating until 2020 he still believes that Ares I is the cheapest way to get past low Earth orbit when paired with its heavy-lift launch companion Ares V. The system, he says, "has the sole failure of costing more than President Obama was willing to provide in the budget".

The committee found that extensive human exploration of the Moon and a direct trip to Mars are not feasible. With a little budgetary leeway, and with the Ares I money put into developing an alternative heavy-lift rocket, the committee determined that there could eventually be a 'deep space' option. Such possibilities could include visits to asteroids, flybys of the Moon and planets, and trips to Lagrangian points - the gravity wells in the Earth-Sun system where some telescopes are situated.

The committee found many ways to extend the operations of the ISS to 2020 in order to satisfy international agreements. What is not obvious is whether, after spending $\$ 2.5$ billion a year to service the ISS in coming years, there would be money for much else. "I dislike pretending that we have goals that are far-reaching and frontier-oriented when we're not willing to set aside money to achieve them," says Griffin.

Obama's 2010 budget guidance did include the caveat that additional money could be requested for the programme pending the Augustine committee's report. Congress, which is working to set those spending figures this autumn, has scheduled hearings on the report for mid-September. So although the committee's job will soon be over, some tough decisions whether to argue for more money, or to accept a more limited programme - are still in store. "The more difficult job is going to be on the president's desk," says Smith.

Eric Hand 